\title{
Análise das Implicações do Conceito de Estâncias Climáticas para os Municípios de São José dos Campos e Campos do Jordão - SP
}

\author{
Analysis of the Implications of the Concept of Climate Resorts for the Municipalities \\ of São José dos Campos and Campos do Jordão - SP
}

Análisis de las implicaciones del concepto de resorts climáticos para los municipios
de São José dos Campos y Campos do Jordão - SP

\author{
Amâncio Rogério Eusébio Cardozo ${ }^{1}$ \\ https://orcid.org/0000-0002-9697-9422 \\ Mário Valério Filho² \\ https://orcid.org/0000-0001-9268-8970
}

\begin{abstract}
RESUMO: O presente estudo tem por objetivo analisar em que medida as características do clima das cidades de São José dos Campos-SP e Campos do Jordão-SP contribuíram para as definições de estâncias climáticas desses municípios, no primeiro quartel do século $\mathrm{XX}$ e em que medida elementos de ordem política e econômica influenciaram tal classificação. Os municípios de São José dos Campos e Campos do Jordão, localizados na Região Metropolitana do Vale do Paraíba e Litoral Norte do Estado de São Paulo, tiveram, em passado recente, a classificação de estância climática e de saúde. Posteriormente, os municípios perderam tais características e revelaram suas novas vocações para polo tecnológico - São José dos Campos -, e turismo - Campos do Jordão. A classificação de estância climática e de saúde foi um elemento vital na (re)construção da infraestrutura desses municípios. A dinamização do setor econômico de São José dos Campos e Campos do Jordão também foi advinda dessa classificação. A questão da classificação climática ou as características do clima foram apenas elementos na concepção de estância climática aos municípios de São José dos Campos e Campos do Jordão, prevalecendo os elementos de ordem econômica e política, com maior peso nessa classificação.
\end{abstract}

PALAVRAS-CHAVE: Planejamento urbano. Estâncias climáticas e de saúde. Ações políticas e econômicas. São José dos Campos. Campos do Jordão.

ABSTRACT: The present study aims to analyze to what extent the climate characteristics of the cities of São José dos Campos-SP and Campos do Jordão-SP, contributed to the definitions of Climatic Resorts of these municipalities, in the first quarter of the 20th century and what is the level of influence of political and economic aspects in this classification. The municipalities of São José dos Campos

\footnotetext{
${ }^{1}$ Mestrando do Programa de Pós-Graduação em Planejamento Urbano e Regional - Universidade Vale do Paraíba. E-mail: rogerio7jack@outlook.com.

2 Doutorado em Agronomia pela Universidade de São Paulo. Professor da Universidade do Vale do Paraíba. Email: mvalerio@univap.br.
} 
and Campos do Jordão, located in the Metropolitan Region of Vale do Paraíba and the North Coast of the State of São Paulo, recently had the classification of climatic resort and health. Subsequently, the municipalities lost these characteristics and revealed their new vocations for technological pole - São José dos Campos - and tourism - Campos do Jordão. The classification of climatic and health resort was a vital element in the (re) construction of the infrastructure of these municipalities. The dynamism of the economic sector of São José dos Campos and Campos do Jordão also came from this classification. The issue of climatic classification or the characteristics of the climate were only elements in the conception of a climatic resort to the municipalities of São José dos Campos and Campos do Jordão, with the economic and political elements with greater weight in this classification prevailing.

KEYWORDS: Urban planning. Climate and health resorts. Political and economic actions. São José dos Campos. Campos do Jordão.

RESUMEN: El presente estudio tiene como objetivo analizar en qué medida las características climáticas de las ciudades de São José dos Campos-SP y Campos do Jordão-SP, contribuyeron a las definiciones de centros turísticos climáticos de estos municipios, en el primer cuarto del siglo XX y en qué Los elementos políticos y económicos influyeron en esta clasificación. Los municipios de São José dos Campos y Campos do Jordão, ubicados en la Región Metropolitana de Vale do Paraíba y la Costa Norte del Estado de São Paulo, tenían en el pasado reciente la clasificación de resort climático y de salud. Posteriormente, los municipios perdieron estas características y revelaron sus nuevas vocaciones para el polo tecnológico, São José dos Campos, y el turismo, Campos do Jordão. La clasificación del recurso climático y de salud fue un elemento vital en la (re) construcción de la infraestructura de estos municipios. La dinamización del sector económico de São José dos Campos y Campos do Jordão también se debió a esta clasificación. La cuestión de la clasificación climática o las características del clima fueron solo elementos en la concepción de un recurso climático para los municipios de São José dos Campos y Campos do Jordão, prevaleciendo los elementos económicos y políticos con mayor peso en esta clasificación.

PALABRAS-CLAVE: Planificación urbana. Centros climáticos y de salud, Acciones políticas y económicas. São José dos Campos. Campos do Jordão.

\section{INTRODUÇÃO}

A preocupação com a salubridade em relação ao lugar é bem antiga, remonta a Hipócrates (aproximadamente 450 a 430 A.C), e seu tratado Ares, Águas e Lugares (RIBEIRO JÚNIOR, 2000). Os "ares da modernidade", isto é, a representação de uma nova realidade, está atrelada à industrialização, à urbanização, ao higienismo e ao sanitarismo. Esses elementos foram introduzidos no Brasil ainda em tempos coloniais, com a transferência da Corte Portuguesa para a Colônia em 1808.

A transferência da Corte Portuguesa exigiu das organizações do governo e das instituições administrativas uma série de mudanças na estrutura urbana do Rio de Janeiro, para sua adaptação, como apontou Carvalho (2014). As medidas de melhoramento e requalificação dos espaços urbanos parece ser o primeiro fator de ressignificação de lugares na América Portuguesa.

Posteriormente, evidenciaram-se outros movimentos sociais e econômicos, tais como a abolição da escravatura que, por sua vez, não incluiu a categoria de ex-escravos no 
mercado de trabalho, marginalizando grandes contingentes populacionais que passaram a habitar os bairros urbanos periféricos sem infraestrutura.

Pinto (2014) mostra que a modernidade no Brasil encontrou um ambiente propenso à proliferação de doenças, mediante a ocupação de áreas por ex-escravos e até escravos foragidos, o aumento populacional com a vinda de mão-de-obra estrangeira, a falta de infraestrutura e a precariedade das condições de saúde. Ressalta-se que não é o espaço ocupado pelo pobre que produz doença, pois a mesma é social, ou seja, não é o pobre que promove a doença, mas sim a ausência do Estado no que se refere ao atendimento das demandas públicas de saúde.

Escravos e imigrantes, de acordo com o autor, possuiam precárias condições de saúde, além de estarem desprovidos de condições sanitárias mínimas. Esse cenário potencializou a propagação das endemias e fez surgir as primeiras Prefeituras Sanitárias como medidas mitigadoras do problema, ressaltou o autor.

As fugas do interior de São Paulo, em especial aquelas para o Quilombo Jabaquara, na cidade de Santos, colocam em rota inversa ex-escravos e imigrantes, ambos em precárias condições de saúde, dentro de um contexto urbano desprovido de condições sanitárias mínimas. Este universo potencializou o desenvolvimento das endemias, que no final do século XIX e início do século $X X$, impôs pesadas perdas humanas não só no Estado de São Paulo. A criação das primeiras Prefeituras Sanitárias, [...], precedeu as Estâncias na forma como são conhecidas atualmente, foi muito estimulada como medida mitigadora ao enfrentamento das enfermidades estabelecidas no universo apresentado (PINTO, 2014, p. 77).

Perante o quadro acima descrito, foram lançadas as bases para a criação das estâncias climáticas e de saúde, como mais uma forma de amenizar os impactos causados pelas precárias condições de saúde. As estâncias parecem ter sido o apêndice das prefeituras sanitárias, ou seja, um instrumento a mais na busca da cura das enfermidades existentes já de forma endêmica.

Conforme descreveu Pinto (2014), o crescimento populacional teve significativo aumento somado à problemática de ocupação do espaço em relação ao inchaço dos grandes centros; talvez isso tenha sido uma das primeiras formas de macrocefalia em território nacional. A relação imigração europeia - crescimento populacional refletiu na Região Sudeste e São Paulo foi o centro que mais presenciou esse crescimento, chegando a 580 mil habitantes em 1920. O processo de industrialização, que mecanizou o campo e causou êxodo rural, além das condições insalubres das fábricas passando pela economia cafeeira, foram os fatores que contribuíram para a formação das primeiras estâncias.

Para Belculfiné (2010), São José dos Campos possuía uma incipiente produção cafeeira, e as condições para sua modernização ocorreram a partir de sua classificação 
Análise das Implicações do Conceito de Estâncias Climáticas para os Municípios de São José dos...

como Cidade Sanatorial e Estância Climática e de Saúde. Seu espaço foi ressignificado a partir de um novo fio condutor, a doença.

As características iniciais de economia exclusivamente agrícola da cidade foram se transformando e uma nova configuração foi se impondo por meio do sanitarismo. Milton Santos (1988, p. 17) ressaltou que "as mudanças que o território vai conhecendo, nas formas de sua organização, acabam por invalidar os conceitos herdados do passado e a obrigar a renovação das categorias de análise".

Para Hammerl (2013), a tuberculose, também conhecida como peste branca, foi o elemento desafiador da ordem social. Havia o temor do contágio, além de moradias insalubres e revoltas populares reivindicando intervenções sanitárias.

Se a epidemia ameaçava o poder de organização do Estado, as medidas de controle exigiam uma reorganização social, com grande influência do discurso higienista. Havia a crença de que lugares insalubres como cortiços, como evidenciado por Chalhoub (1996) deveriam ser eliminados de áreas centrais. Nesse contexto, Hammerl (2013, p. 1) aponta a relação entre teorias médicas e aspectos geográficos e climáticos:

Nos cinquenta primeiros anos do século $X X$, a tísica e suas vítimas tornaram-se objetos de preocupação no contexto brasileiro. As ações direcionadas para seu controle foram embasadas nas teorias médicas que aliavam os aspectos geográficos e climáticos como fatores predominantes na organização social e no controle epidêmico.

Campos do Jordão tornou-se estância climática e hidromineral pela Lei no 2140, de 01 de outubro de 1926, o que pode também ter redesenhado o espaço urbano da cidade em relação à sua infraestrutura (SÃO PAULO, 1926).

As perguntas centrais desta análise são: havia estudos dentro das Ciências Atmosféricas que pudessem classificar as localidades - Sub-Regiões da Região Metropolitana do Vale do Paraíba e Litoral Norte - RMVPLN - onde se encontram São José dos Campos e Campos do Jordão, como estâncias climáticas? Em que medidas os interesses de ordem econômica e política interferiram na classificação de estância?

O recorte espacial analisado compreende os municípios de São José dos Campos-SP e Campos do Jordão-SP, pois ambos apresentaram marcante momento histórico quando, no início do século XX, tiveram papel preponderante em relação ao tratamento de doenças do peito que assolavam o país.

Esses municípios foram classificados como estâncias climáticas e de saúde, tendo alterações em seu desenvolvimento econômico e de infraestrutura. Zanetti et al. (2010) tratou desse momento histórico dos municípios. 
A classificação de estância provém dos climas dos municípios, contudo o contexto histórico aponta elementos de ordem política e econômica que tiveram peso na decisão dessa classificação.

O presente artigo procura mostrar que elementos de ordem política, social e sobretudo econômica, tiveram peso igual senão maior que os de elementos climáticos para a classificação de estâncias dos municípios de São José dos Campos e Campos do Jordão, mesmo que este último apresentasse clima diferenciado.

\section{ÁREA DE ESTUDO}

A área de estudo compreende o município de São José dos Campos, situado na RMVPLN - SP (Figura 1), classificado como estância climatérica, hidromineral e de saúde pelo Decreto o 7007 de 1935. Foi durante o Governo Vargas que os investimentos chegaram, estimulados pela inauguração do maior sanatório do país, o Vicentina Aranha, erigido em 1924 (SÃO JOSÉ DOS CAMPOS, 2019).

Figura 1 - Localização da área de estudo, Região Metropolitana do Vale do Paraíba e Litoral Norte do Estado de São Paulo, em destaque os municípios de Campos do Jordão e São José dos Campos-SP

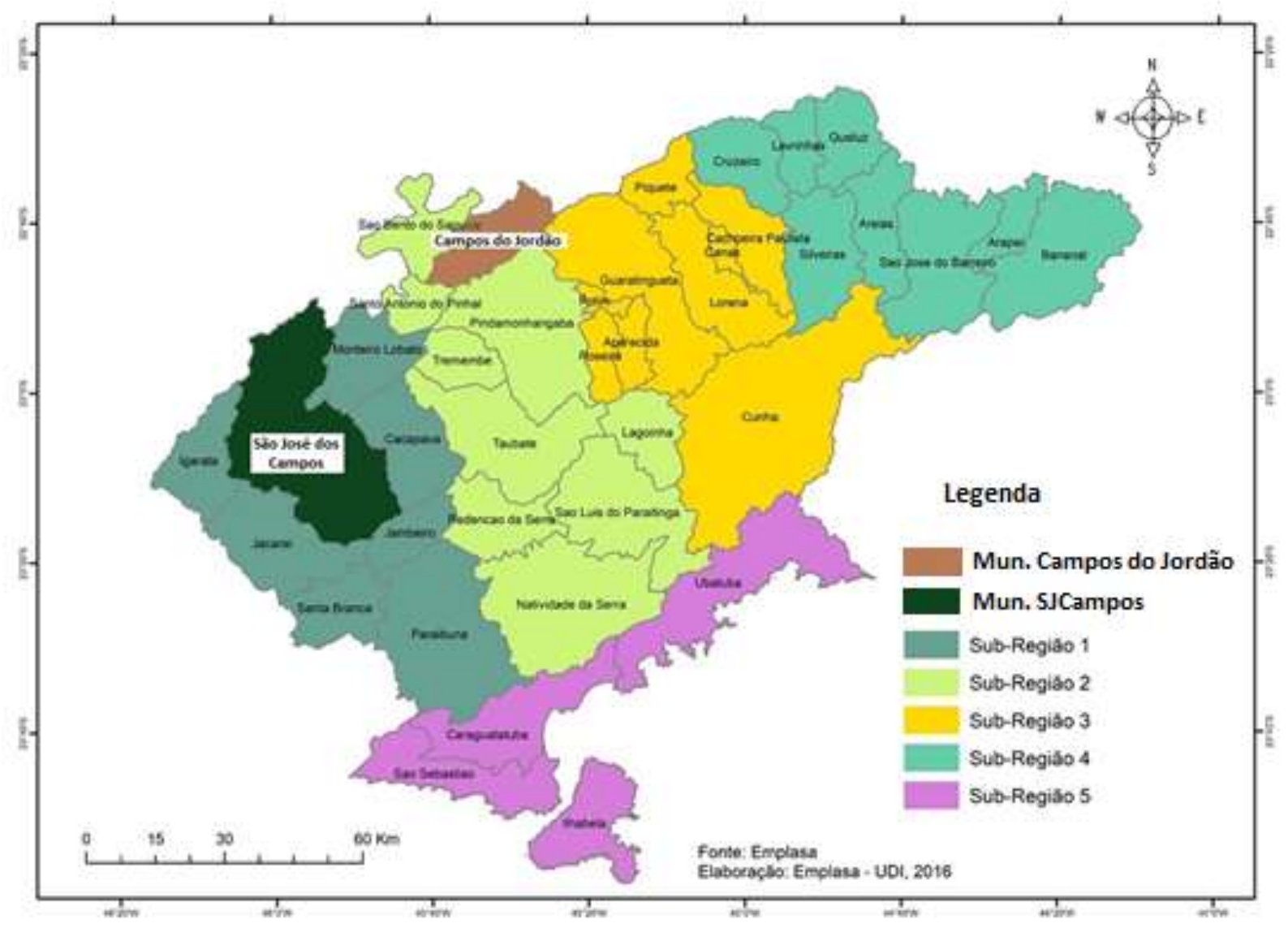

Fonte: EMPLASA, 2016. 
Análise das Implicações do Conceito de Estâncias Climáticas para os Municípios de São José dos...

Outro município foco da pesquisa é Campos do Jordão, também situado na RMVPLN (Figura 1), classificado como estância hidromineral e de saúde em 1926, por meio da Lei $n^{\circ}$ 2.140 de 01/10/1926. O município de Campos do Jordão está localizado no alto da Serra da Mantiqueira, a 1.628 metros de altitude, enquanto São José dos Campos está localizado em região de média altitude, entre 550 a 690 metros acima do nível do mar.

No caso de São José dos Campos, a fase sanatorial teve início, oficialmente, em 1935 com a decretação de Estância Climática e perdurou até 1950, quando ocorreu o início do processo de sua segunda fase de industrialização. Quando o município se tornou estância climática e de saúde ocorreu a migração de pessoas de várias regiões do país para a cidade, que passava por forte crise econômica oriunda da baixa produção de café, e isto acabou por dinamizar a economia local e estruturar o espaço urbano pela lógica sanitarista, o que levou a um planejamento urbano estratégico. O zoneamento urbano (Quadro 1) foi a forma de promoção da dinâmica econômica. Isso fica evidente quando, em 1932, as preocupações dos gestores com as leis de zoneamento, o êxodo rural e a chegada de doentes, dividiram o município em 3 zonas: residencial, comercial e sanatorial, evidenciado no Ato N.110. Em 1933 houve acréscimo de uma nova zona, a industrial, estabelecida em 11/10/1938 pelo prefeito e engenheiro sanitarista Francisco José Longo por meio do Ato N.14 (CHUSTER, 2010).

Quadro 1 - Reprodução do Código de Obras de 1954

Das Zonas, Bairros e Núcleos

Artigo 162. - o município será dividido em zonas urbana e suburbana e rural.

Artigo 163. - as zonas urbana e suburbana da cidade serão subdivididas em:

Zona Industrial

Zona Comercial

Zona Residencial

Zona Sanatorial

Zona Aeronáutica

Artigo 164. - Em nenhuma das zonas Industrial, Comercial ou Residencial, será permitida a instalação de sanatórios, pensões senatoriais e congêneres destinadas a manter pessoas de moléstia contagiosa.

Artigo 165. - Os perímetros das zonas e dos bairros serão fixados por ato do Prefeito e revistos periodicamente

Fonte: Chuster (2010).

São José dos Campos foi transformada em estação de tratamento de doenças no início do século XX. Há teorias para a justificativa dessa característica do município, entretanto nenhuma delas apresenta embasamento sólido. O desenvolvimento do município esteve atrelado a climatoterapia:

Até então fora do circuito de interesses do estado de São Paulo, a atração de doentes pela climatoterapia - terapia baseada no clima -, sustentou não 
só projetos políticos, como uma gama de ideias de infraestrutura para viabilizar o desenvolvimento do município, como a construção de ferrovia para o transporte dos doentes e de equipamentos para a instalação dos hospitais (MENEGHINI; ZANETTI; GUIMARÃES, 2019, p. 20).

Segundo Meneghini, Zanetti e Guimarães (2019), desde 1900 existia a ideia da construção de sanatórios, havendo até projetos não aprovados pelo governo estadual que alegava ser por demais oneroso. Perante esse impasse, o município ainda tentou o estímulo de grupos econômicos e entidades particulares para reconsideração do projeto, pois alegava-se a incapacidade sanitária das pensões.

No interior da cidade conviviam duas correntes contrárias, as que aceitavam a ideia do município como estação de tratamento de doenças e outra contrária ao fato, esse cenário fez coexistir solidariedade/acolhimento e receio/preconceito. A imprensa local propagou o medo devido a possibilidade da invasão da cidade por doentes provenientes de todo o país, contudo o Sanatório Vicentina Aranha (Figura 2) foi erigido tendo sua inauguração em 1924. (ZANETTI et al., 2010).

Figura 2 - Aspectos visuais do Sanatório Vicentina Aranha (1950)
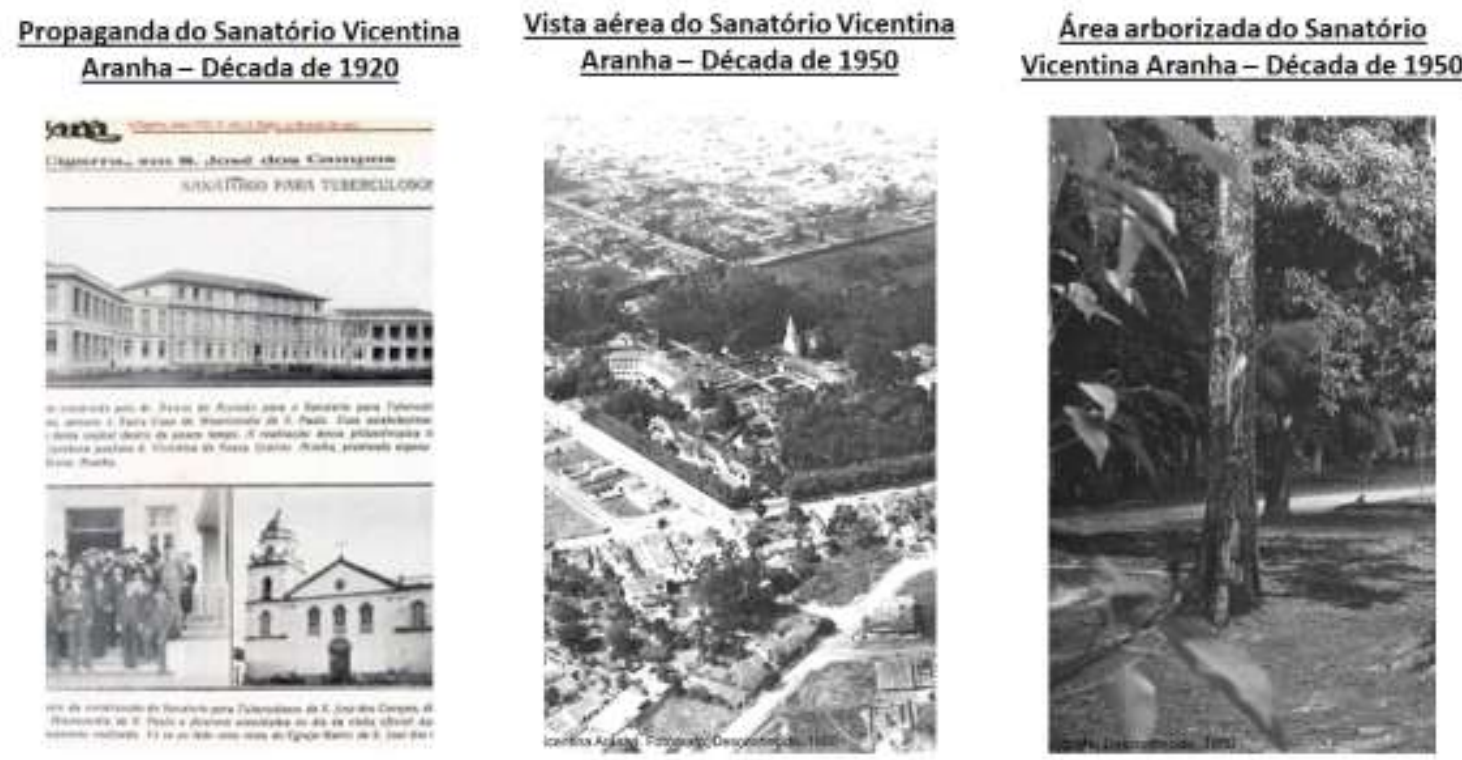

Fonte: dados da pesquisa - Pró-memória (VICENTINA... 2017).

Se havia uma propaganda contrária à transformação de São José dos Campos em estação de tratamento de doenças, também havia uma propaganda a favor, exaltando os ares da cidade como bom para o tratamento da tuberculose.

O marketing em jornais e revistas corroborava a fama dos ares de São José dos Campos, o que seria oportuno para se atrair pessoas e investimentos e, posteriormente realizar melhoramentos urbanos e a modernização do espaço (QUADRO et al., 2010). 
Análise das Implicações do Conceito de Estâncias Climáticas para os Municípios de São José dos...

A cidade de Campos do Jordão possuía a imagem de localidade acolhedora e de espírito assistencialista no início do século XX, essa representação ocorreu quase em nível de senso comum, sendo forjada por médicos e empreendedores. Campos do Jordão está localizado na RMVPLN, mais precisamente nos contrafortes da Serra da Mantiqueira. A partir de sua formação, houve fluxos de deslocamentos das cidades do Vale do Paraíba Paulista à Serra da Mantiqueira e ao Sul do Estado de Minas Gerais (MENEGHINI; ZANETTI; GUIMARÃES, 2019).

A procura pelo município pode estar relacionada a alguns fatos, dentre eles destacamse três: a chegada do médico tisiologista Dr. Mário Nunes Galvão, que veio em busca de tratamento e curou-se, tornando-se uma referência para os que estavam em busca da cura; o acesso à cidade por vias férreas devido a sua localização (eixo Rio-São Paulo) e a infraestrutura que contava com serviços de água, telefone, iluminação e a Santa Casa de Misericórdia (BELCULFINÉ, 2010).

O clima de montanha e a altitude de 1.628 metros permitiram a comparação de Campos do Jordão com as cidades de Davos Platz, nos Alpes Suíços, e Chamonix, uma estância francesa. Davos Platz foi considerada referência de temperatura para tratamento pulmonar e Chamonix foi caracterizada pela pureza do ar e pelo teor de oxigenação e ozônio. Essa comparação rendeu a imagem de "Suíça Brasileira" ao município (MENEGHINI; ZANETTI; GUIMARÃES, 2019, p. 22).

A fase sanatorial jordanense perdurou de 1924 a 1950 e esteve associada à imagem de "Suíça Brasileira", sendo promovida pela política do então governador do Estado de São Paulo, Adhemar de Barros. O desenvolvimento da política senatorial, por sua vez, estava atrelado aos preceitos higienistas implicando na setorização do município (VIANNA; ZANETTI; PAPALI, 2014).

\section{METODOLOGIA}

Este estudo se valeu de referências bibliográficas sobre a formação histórica dos municípios de São José dos Campos e Campos do Jordão, no tocante à relação desses municípios com a questão epidêmica que assolou o país. Também se utilizou os conceitos de clima e de estância para o desenvolvimento do mesmo, bem como foi imprescindível o levantamento de dados contidos nos textos sobre o contexto histórico sanatorial dos municípios.

Buscou-se mostrar as classificações climáticas, já existentes à época da fase senatorial, e sua quase inexistente influência em relação à definição de estância climática. Por último a técnica aqui escolhida foi o estudo de caso por esta se propor a identificar um 
problema, analisar as evidências e desenvolver argumentos lógicos se valendo da coleta de dados qualitativos não sendo uma linha rígida de investigação.

\section{RESULTADOS E DISCUSSÃO}

À época da instituição das cidades de São José dos Campos e Campos do Jordão como estâncias climáticas e de saúde, ainda não havia ocorrido a sistematização dos métodos de medição e registros dos fenômenos climáticos.

Houve observações e registros do clima brasileiro desde a época de sua descoberta ou "achamento", viajantes vieram com finalidades variadas, catequizar indígenas, coletar plantas ou animais, conhecer o solo e os acidentes geográficos, desenhar paisagens e sobretudo explorar riquezas naturais. De acordo com Araki (2012) já por esta época havia a ideia da existência do Paraíso Terrestre. As terras na América corroboravam essa ideia, pois se caracterizavam como locais de ares saudáveis, clima benigno e terreno fértil, dentre outras características.

Evidencia-se que havia uma propaganda em relação às novas terras, mesmo que um pequeno entrave tenha sido detectado, pois a ideia de "paraíso" chocava-se com dogmas cristãos, exaltou-se a qualidade da terra e considerou-se o clima como um "segundo" paraíso mantendo a propaganda. Mesmo com os atributos da nova terra e a propaganda a respeito dela havia também o seu lado "infernal": "Apesar das propagandas da nova terra, deleitosa e temperada, ela era sujeita aos ventos mortíferos, perigosos e doentios, sendo a exposição contínua durante alguns dias, morriam muita gente entre os portugueses e índios" (ARAKI, 2012, p. 210).

Pelo acima descrito, percebe-se que as propagandas em relação a paisagem e o clima remontam a época da colônia, como também houve registros de séries temporais (Quadro 2) ainda que de forma empírica, como mostrou Sant'Anna Neto (2003) assinalando séries temporais nos séculos XVIII e XIX, referentes ao Estado de São Paulo.

A classificação climática atual está vinculada à coleta de dados por vários meios técnicos e, ao que tudo indica, no ano em que surgiu o modelo climático de Köppen essas observações ocorriam de forma empírica e interpretativa. No que concerne aos conceitos de clima e tempo parecem ter tido a mesma definição da dos dias atuais.

Segundo Ynoue et al. (2017), em Ciências Atmosféricas, o conceito de tempo referese ao estado momentâneo da atmosfera e o conceito de clima refere-se ao estado médio da atmosfera, obtidos pela média dos eventos de tempo durante um longo período.

As informações para se determinar o clima são obtidas por meio das estações meteorológicas que registram variáveis atmosféricas tais como temperatura do ar, umidade 
relativa, pressão atmosférica e precipitação (YNOUE et al., 2017). Para a Organização Meteorológica Mundial (OMM) a definição do conceito de clima estabelece que:

A média das variáveis supracitadas em períodos de 30 anos. Devido a superfície terrestre não ser homogênea, existem diferentes fatores ou controles climáticos implicando em climas variados no interior de uma mesma latitude. De forma sucinta, os fatores ou controle climáticos são as Estações do Ano, a incidência de radiação solar, a latitude e a altitude, as correntes oceânicas, os padrões de circulação atmosférica e os ciclos diurnos de temperatura. O clima de um determinado local depende dos controles, no âmbito das Ciências Atmosféricas, para facilitar o mapeamento de regiões com climas semelhantes são definidos critérios conhecidos como esquemas ou modelos de classificação climática (YNOUE et al., 2017, p. 133).

Quadro 2 - Séries temporais de São Paulo nos séculos XVIII e XIX

\begin{tabular}{|l|l|l|l|}
\hline \multicolumn{1}{|c|}{ Período } & \multicolumn{1}{|c|}{ Local } & \multicolumn{1}{|c|}{ Autor } & \multicolumn{1}{c|}{ Descrição } \\
\hline $\begin{array}{l}1788- \\
1789\end{array}$ & São Paulo - SP & Sanches Dorta & Não consta \\
\hline $\begin{array}{l}1845- \\
1858\end{array}$ & São Paulo - SP & $\begin{array}{l}\text { Brigadeiro } \\
\text { Machado }\end{array}$ & $\begin{array}{l}\text { Dados horários (6:00 e 15:00h) da } \\
\text { temperatura do ar }\end{array}$ \\
\hline $\begin{array}{l}1870- \\
1875\end{array}$ & São Paulo - SP & $\begin{array}{l}\text { Germano D } \\
\text { 'Annecy }\end{array}$ & Dados diários de temperatura \\
\hline $\begin{array}{l}1879- \\
1882\end{array}$ & São Paulo - SP & Henry Joiner & Dados diários de temperatura \\
\hline $1886-\mathrm{xx}$ & $\begin{array}{l}\text { Estado de São } \\
\text { Paulo }\end{array}$ & IGG & Dados meteorológicos \\
\hline $1889-\mathrm{XX}$ & Campinas & IAC & Dados meteorológicos \\
\hline
\end{tabular}

Fonte: adaptado de Sant’Anna Neto (2003).

O modelo de classificação de Köppen (Quadro 3) foi elaborado em 1918, algumas versões foram adaptadas sendo muito utilizadas em livros didáticos de Meteorologia, Climatologia e Geografia Regional. No modelo de Köppen, cada clima é definido de acordo com os valores de temperatura e precipitação calculados em termos anuais ou mensais, também é possível identificar o grupo climático e o subgrupo de qualquer localidade por meio de registros de temperatura e precipitação (YNOUE et al., 2017, p. 135). O Quadro 3 mostra apenas os cinco grupos climáticos de Köppen.

Silva Júnior et al. (2017) mostrou que Charles Warren Thornthwaite, em 1948, desenvolveu a metodologia de classificação climática onde são analisadas variáveis como precipitação pluviométrica, radiação solar, temperatura e umidade relativa do ar.

Não se sabe se o modelo de classificação climática de Köppen (1918) teve alguma influência na classificação de estância climática e hidromineral de Campos do Jordão (1926) e de São José dos Campos e, provavelmente, o modelo de Thornthwaite (1948) até pela data que foi concebido não teve influência alguma nessa classificação. 
Quadro 3 - Os cinco grupos climáticos de Köppen. Os grupos A, C, D e E são definidos com base na temperatura, e o grupo B tem a precipitação como seu critério principal

\begin{tabular}{|l||}
\hline A - Climas tropicais úmidos \\
Todos os meses possui temperatura média maior que $18^{\circ} \mathrm{C}$ \\
Não existe estação de inverno "de verdade" \\
\hline B - Climas secos \\
A precipitação anual é menor que $500 \mathrm{~mm}$ \\
A evaporação potencial e a transpiração excedem a precipitação \\
\hline \hline C - Climas úmidos de latitudes médias com invernos amenos \\
Verões quentes a muito quentes, com invernos amenos \\
A temperatura média do mês mais frio é menor que do que $18^{\circ} \mathrm{C}$ e maior do que $-3^{\circ} \mathrm{C}$ \\
\hline D - Climas úmidos de latitudes médias com invernos severos \\
Verões quentes, com invernos frios \\
A temperatura média do mês mais quente excede $10^{\circ} \mathrm{C}$ \\
A temperatura média do mês mais frio é menor do que $-3^{\circ} \mathrm{C}$ \\
\hline E - Climas polares \\
Invernos e verões extremamente frios \\
A temperatura do mês mais quente é menor do que $10^{\circ} \mathrm{C}$ \\
Não há verão "de verdade" \\
\hline \hline
\end{tabular}

Fonte: adaptado de Ynoue et al. (2017).

O fato de haver tido observações e registros sobre os elementos climáticos desde os tempos coloniais podem ter influenciado a classificação de estância nos municípios de Campos do Jordão e de São José dos Campos.

\section{ESTÂNCIA CLIMÁTICA E DE SAÚDE}

De acordo com Lefebvre (2001), sob uma ótica econômica, a divisão social do trabalho, em âmbito urbano, permite uma maior conexão entre os diversos elementos que constituem o capital. Os trabalhos divididos no interior das cidades são complementares uns aos outros e criam a necessidade de conexão e, assim sendo, o valor do solo urbano ocorre de maneira diferenciada de outras mercadorias, como explicou Freitas (2005, p. 2):

[...] devemos entender as formas como se dão a valorização do solo urbano, que se realiza de forma diferenciada de outras mercadorias. Como se trata de uma mercadoria diferenciada das demais, pelo fato de a terra não ser considerada um capital, mas sim um equivalente de capital, seu processo de valorização não é decorrente de forma direta do trabalho, mas sim das formas de como se dão a sua apropriação e uso.

Ao longo dos anos e com o advento da cidade industrial, as cidades cresceram, bem como os conflitos em seu interior, e as intervenções para garantir o status quo se deram por meio do urbanismo, e uma importante peça foi a ordenação do solo, sendo o zoneamento um instrumento de mediar e regular conflitos e demandas das cidades (CHUSTER, 2010). 
Análise das Implicações do Conceito de Estâncias Climáticas para os Municípios de São José dos...

Para Melo (2016), os assentamentos brasilieiros cresceram entre as décadas de 1940 a 1980 , e a taxa de urbanização passou de $26,35 \%$, para $68,86 \%$ nesses 40 anos. A ascensão de Getúlio Vargas ao poder contribuiu para o crescimento dos centros urbanos, sua política de grandes investimentos na indústria nacional iniciou a ruptura com o modelo econômico agrário-exportador, propiciando o êxodo rural.

Ressalta-se que a rede de cidades brasileiras teve por característica a hierarquização, e São Paulo tornou-se hegemônico no setor industrial. O desenvolvimento da indústria estava vinculado ao aumento da produção do setor secundário e de infraestrutura, no entanto a industrialização se concentrou em áreas específicas, atraindo um enorme contingente que gerou um modelo de desenvolvimento desestruturado.

Foi durante a política de aldeamento, em tempos coloniais, por volta do século XVI, que surgiu a aldeia de São José dos Campos. Em 1767 a aldeia foi elevada à condição de Vila, denominada Vila de São José do Parayba, um lugarejo pacato com uma economia de subsistência que perdurou até meados de 1850. São José dos Campos nunca ocupou um lugar de destaque na economia cafeeira do final do século XIX, possuindo apenas lavouras médias e pequenas. A industrialização local nunca esteve vinculada ao complexo cafeeiro do Vale do Paraíba Paulista e, no século $X X$, a cidade se tornou proeminente com a centralização e a concentração de investimentos, população e equipamentos, marcando a fase sanatorial, como apontaram Papali, Del Olmo e Zanetti (2007).

De certa maneira, São José dos Campos possuia uma incipiente economia industrial e a partir do advento da tuberculose, uma vasta gama de atores sociais coexistiram no município durante a fase sanatorial (1924-1960), além dos portadores da enfermidade existiam farmacêuticos, religiosos, tisiologistas, sanitaristas, autoridades, comerciantes e políticos, dentre outros, destacando o setor terciário.

Uma nova economia orbitava ao redor do tratamento dos tuberculosos, ou seja, setores de alimentação, vestuário e calçados, farmácias, transporte etc., justificando Código de Obras de 1954 como visto acima. No entanto o município não se isentou da questão do desenvolvimento desestruturado e dos conflitos sociais.

Rodrigues ([2008]) mostrou que a cidade de Campos do Jordão, localizada na Serra da Mantiqueira, nasceu de um povoado que se tornou distrito da cidade de São Bento do Sapucaí - SP, e teve sua autonomia administrativa em 1934. As características de clima serrano de Campos do Jordão renderam-Ihe sanatórios e uma estrada de ferro, pois a cidade poderia ser um local de descanso e simultaneamente um local de tratamento da tuberculose, assim o espaço interno foi se redesenhando como mostrou a autora:

[...] em 1924, A Cigarra estampa um longo artigo,"Campos do Jordão, o que será dentro em pouco a Suíça brasileira", em que o autor compara o lugar com os congêneres europeus e explicita as vantagens climáticas por ele 
oferecidas. [...] A matéria termina apontando um futuro promissor, que resultaria da eletrificação da estrada de ferro e do aumento do número de viagens; das ações urbanizadoras promovidas pela Companhia Cam os do Jordão; e, sobretudo, da criação da Prefeitura Sanitária, por meio da qual o governo do estado poderia tomar medidas de promoção de melhoramentos urbanos, de higiene e outras, como a concessão para instalação de sanatórios, hotéis, pensões e divertimentos, oferecendo o "conforto e prazer indispensáveis à vida moderna" (RODRIGUES, [2008], p. 8).

A questão principal foi a característica destas cidades estarem voltadas para a cura climática, o que propiciou o desenvolvimento do setor terciário com a implantação de sanatórios, pensões e farmácias, dentre outros comércios e serviços. A partir disto fica evidente o fator comum entre São José dos Campos e Campos do Jordão, no que se refere à dinâmica de uso e ocupação do solo, com primazia para o setor terciário. Como o país vivia assolado por endemias a oferta de centros de recuperação se fez presente em Campos do Jordão e São José dos Campos que, ao ofertarem a cura, também desenvolveram infraestruturas para abrigar enfermos e simultaneamente oferecer serviços diversos e comécio.

Segundo Pinto (2014), vários fatores potencializaram o aumento de endemias no Brasil, dentre eles destacaram-se: o aumento populacional fomentado pela imigração, o abolicionismo e a falta de investimentos em infraestrutura.

Ainda de acordo com o autor, a busca pela cura não foi limitada apenas a questões sanitarias ou ambientais, sendo estas promovidas pelos mais variados motivos. Em determinados locais onde havia enfermidade que afetava o sistema respiratório, bons resultados foram obtidos. Essas localidades possuiam características diferenciadas de clima.

Para o autor, o primeiro a perceber essa relação foi a iniciativa privada, ao instalar os primeiros sanatórios no município de Campos do Jordão. A partir desse fato, o Estado percebe a necessidade de investimentos nessa área, legislando a favor de determinados municipios: "Sob esta ótica em 01 de outubro de 1926, o Doutor Carlos de Campos, então Presidente do Estado de São Paulo, promulga a Lei 2.140, autorizando a criação de uma Prefeitura Sanitária em Campos do Jordão" (PINTO, 2014, p. 29).

O autor ainda destacou outros pontos do documento, tais como a necessidade de planejamento por parte do Poder Executivo, quando as diretrizes deveriam ser traçadas de acordo com o conhecimento que se possuia no período, no tocante às condições de habitabilidade. De forma empírica promoveu-se as melhorias nas condições locais. Também havia a intenção de relacionar o campo da saúde com o turismo de forma que houvesse uma distribuição equilibrada dos investimentos, mesmo com a inexistência de um projeto de implantação de estâncias. 
Análise das Implicações do Conceito de Estâncias Climáticas para os Municípios de São José dos...

A função das primeiras estâncias em São Paulo foi de caráter sanitário, a prioridade era o tratamento de enfermidades pulmonares (PINTO, 2014). Na Europa definir os padrões de estância climática é relativamente mais fácil que nos trópicos, em termos de classificação, pois as estações são mais marcadas na região temperada. A paisagem europeia atuou no imaginário europeu, se antes as montanhas com neves eternas eram vistas com locais inadequados, causando repugnância nas pessoas, a partir do século XIX passaram a ter uma admiração estética que se deveu aos melhoramentos na comunicação e aos avanços da ciência. O novo sentimento de admiração viria posteriormente justificar a criação de estâncias (RAIMUNDO et al., 2010).

\section{CLIMATOTERAPIA}

A tétrade - doença - morte - esperança - propaganda, foram as palavras chaves no período histórico da cidade de São José dos Campos e quiça Campos do Jordão. Zanetti et al. (2010) mostrou, por exemplo, a força da propaganda quando da fama de "bons ares" e "cidade esperança" relativas à cidade de São José dos Campos, onde tais jargões se espalharam vertiginosamente em fins do século XIX e início do século XX.

O marketing em revistas e jornais foi um instrumento poderoso na atração de doentes para o município de São José dos Campos, o que modificou sua economia e infraestrutura, e os doentes foram um elemento deverás importante no processo. No entanto, se por um lado traziam movimentação econômica, por outro também traziam problemas, uma vez que nem todo doente de tuberculose dispunha de recursos para as despesas e acabavam por se tornar mendigos e nem todos os doentes dispunham de vagas em pensões e sanatórios num primeiro momento (QUADRO et al., 2010).

A morte semelhante à esperança movimentaram o mercado na cidade de São José dos Campos. Serviços funerários e farmácias, tratamento médico e venda de tônicos, além de outros diversos serviços, passaram a compor a economia local.

Algumas correntes da literatura médica, a partir do século XVIII, vinculavam 0 tratamento da tuberculose à salubridade do clima, e isto permeou a transferência compulsória de doentes para locais de tratamento, as denominadas estâncias climatéricas. Acreditava-se que locais com elevadas altitudes e baixas temperaturas seriam propícios à cura da tuberculose. Campos do Jordão até apresenta tais características, no entanto São José dos Campos está distante desses parâmetros topográficos, mas a propaganda instaurada no início do século XX pela imprensa local e pelos poderes públicos fazia acreditar que a cidade era detentora de um clima maravilhoso para a cura da tuberculose (QUADRO et al., 2010). 
A relação clima/saúde remonta ao ano de 1859, com os conceitos de tratamento climático em locais de altitude, desenvolvidos por Brehmer. Acreditava-se que o bacilo não resistiria às baixas concentrações de oxigênio (VIANA et al., 2010). O quanto isso procedeu ou não teve pouca importância na visão dos doentes, pensando que qualquer atitude em prol da cura seria válido.

$\mathrm{Na}$ busca do alívio do sofrimento acredita-se em quase tudo, e esse cenário poderia ter corroborado a aceitação da propaganda da época, atraindo contigentes para as cidades de São José dos Campos e Campos do Jordão.

\section{CONSIDERAÇÕES FINAIS}

Como se pôde perceber pela análise dos autores, os municípios de São José dos Campos e Campos do Jordão, considerados como estâncias climáticas e de saúde, foram instituídos com critérios de classificação climáticas da época, e os diversos registros atestam que se conhecia o clima do Vale do Paraíba, mesmo que de forma empírica. Essas localidades foram o refugio de doentes tísicos, talvez na esperança da cura e, como ainda eram locais de pouca urbanização e de economia rural, soassem como "bons ares" na ajuda da recuperação da saúde. Deve-se levar em consideração que o país estava assolado por endemias e havia a necessidade de providências, sobretudo a descentralização da doença nos grandes centros.

Os investimentos, sejam de iniciativa privada de início, como no caso de Campos do Jordão, sejam de forma estatal, foram as medidas para a promoção de sanatórios e permearam as prefeituras sanitáristas. Estava, dessa forma, estabelecida a "Raccoon City" local - na série de filmes Resident Evil, Raccoon City foi uma grande metrópole construída pela Umbrella Corporation, utilizada para a realização de pesquisa científica e experimentação, possuindo excelente serviço funeral e uma vasta rede de hospitais. A partir desse contexto, o desenvolvimento de infraestrutura de ambos municipíos pôde ocorrer. Posteriormente, por meio dessa base, surgiu uma nova configuração econômica, caracterizando as vocações dos municípios como tecnológica, no caso de São José dos Campos e turística, como no caso de Campos do Jordão.

Mediante a contextualização política-econômica da época, somado ao imaginário popular e ao fato de que alguns municípios têm um clima diferenciado, no caso aqui Campos do Jordão, pode-se inferir porque as cidades foram consideradas como estâncias climáticas, propícias ao tratamento e a cura da tuberculose pulmonar, sendo o clima apenas parte do contexto, havendo outros elementos de ordem sóciopolítica e sócioeconômica que interferiram nessa classificação. 
Análise das Implicações do Conceito de Estâncias Climáticas para os Municípios de São José dos...

A questão da classificação climática ou as características do clima foram um mero elemento na concepção de estância climática aos municípios de São José dos Campos e Campos do Jordão, prevalecendo os elementos de ordem econômica e política com maior peso nessa classificação, somente a fama de "bons ares", como no caso de São José dos Campos não era suficiente para a cura, não havia infraestrutura adequada para o tratamento da tuberculose em período anterior ao decreto de estância, e mesmo nos primeiros anos pós-decretação, a ausência dessa infraestrutura se fazia presente. Zanetti et al. (2010) mostraram que diversos doentes se alojavam em pensões sem um mínimo de condições para a obtenção da cura.

A infraestrutura só se desenvolveu após 1935, com o planejamento sanitário, e a dinamização do setor econômico também pôde ser observada, nesse sentido a doença foi apenas o ingrediente, o clima o tempero e a mistura resultou no "bolo" da modernidade local.

\section{REFERÊNCIAS}

ARAKI, Ricardo. A história do clima de São Paulo. 2012. Tese (Doutorado em Geografia) Instituto de Geociências, Universidade Estadual de Campinas, Campinas, SP, 2012.

BELCULFINÉ, Douglas Carlyle. São José dos Campos na fase senatorial: humanismo e determinação. In: ZANETTI, Valéria (org.). Fase sanatorial de São José dos Campos: espaço e doença. São José dos Campos, SP: UniVap, 2010. p. 39-50.

CARVALHO, Amanda Lima dos Santos. O Rio de Janeiro a partir da chegada da Corte Portuguesa: planos, intenções e intervenções no século XIX. Paranoá: Cadernos de Arquitetura e Urbanismo, Brasília, DF, n. 13, p. 55-63, 2014.

CHALHOUB, Sidney. Cidade febril: cortiços e epidemias na Corte imperial. São Paulo: Companhia das Letras, 1996.

CHUSTER, Vitor. Zoneamento e urbanização da Cidade de São José dos Campos na fase senatorial. In: ZANETTI, Valéria (org.). Fase sanatorial de São José dos Campos: espaço e doença. São José dos Campos, SP: UniVap, 2010. p. 133-162.

EMPLASA. Empresa Paulista de Planejamento Metropolitano. Região Metropolitana do Vale do Paraíba e Litoral Norte. 2016. Disponível em: https: //www.emplasa.sp.gov.br/RMVPLN. Acesso em: 18 nov. 2018.

FREITAS, César Augustus Labre Lemos de. O processo de valorização do solo urbano: formação e apropriação da mais-valia. In: COLÓQUIO INTERNACIONAL MARX E ENGELS, 4., 2005, Campinas. Trabalho apresentado [...]. Campinas: UNICAMP, 2005. p. 1-10.

Disponível em:

https://www.unicamp.br/cemarx/ANAIS\%20IV\%20COLOQUIO/comunica\%E7\%F5es/GT2/gt 2m1c2.pdf. Acesso em: 15 set. 2020.

HAMMERL, Priscyla Christine. Campos do Jordão (SP): de estância de saúde à estância turística. In: CASTRO, Celso; GUIMARÃES, Valeria Lima; MAGALHÃES, Aline Montenegro. (org.). História do turismo no Brasil. Rio de Janeiro: FGV, 2013. p. 165-176.

LEFEBVRE, Henri. A cidade do capital. Rio de Janeiro: DP\&A, 2001. 
MELO, Felippe Pessoa de. Risco ambiental e ordenamento do território em Garanhuns - PE. 2016. Tese (Doutorado em Geografia) - Universidade Federal de Sergipe, São Cristóvão, 2016.

MENEGHINI, Renata; ZANETTI, Valéria; GUIMARÃES, Antônio Carlos. Memórias de uma tragédia urbana em Campos do Jordão/SP: amostra de relações permeadas pela condição de vulnerabilidade social. ACTA Geográfica, Boa Vista, v. 13, n. 31, p. 19-35, jan. / abr. 2019.

PAPALI, Maria Aparecida; DEL OLMO, Maria José Acedo; ZANETTI, Valéria. São José dos Campos e sua história. São José dos Campos: Pró-memória, 2007. Disponível em: http://www.camarasjc.sp.gov.br/promemoria/historia-sjc/. Acesso em: 19 set. 2020.

PINTO, Silvio Luiz Cardoso. A questão das estâncias climáticas no Estado de São Paulo: Morungaba como estudo de caso. 2014. Dissertação (Mestrado em Semiótica e Linguística Geral) - Faculdade de Engenharia Civil, Arquitetura e Urbanismo, Universidade Estadual de Campinas, Campinas, SP, 2014. Disponível em: http://www.repositorio.unicamp.br/handle/REPOSIP/258081. Acesso em: 8 ago. 2019.

QUADRO, Carlos Eduardo de; COSTA, Suele França; ALMEIDA SILVA, Douglas de; ZANETTI, Valéria. O espírito empreendedor: São José dos Campos vendendo saúde (18901940). In: ZANETTI, Valéria (org.). Fase sanatorial de São José dos Campos: espaço e doença. São José dos Campos, SP: UniVap, 2010. p. 259-283.

RAIMUNDO, Sidnei; ALMEIDA, Marcelo Vilela de; SOLHA, Karina Toledo; CARVALHO, Mariana Aldrigui. Análise da cronologia de criação das estâncias turísticas no Estado de São Paulo. In: SEMINÁRIO DA ASSOCIAÇÃO NAÇIONAL PESQUISA E PÓS-GRADUAÇÃO EM TURISMO, 7., 2010, São Paulo, SP. Anais [...]. São Paulo: ANPTUR, 2010. p. 1-13. Disponível em: https://www.anptur.org.br/anais/anais/files/7/28.pdf. Acesso em: 19 set. 2019.

RIBEIRO JÚNIOR, Wilson A. Coleção hipocrática / de ares, águas e lugares 12 e 16. São Carlos: Graecia Antiqua, 2000. Disponível em: http://greciantiga.org/arquivo.asp?num=0246. Acesso em: 8 set. 2019.

RODRIGUES, Marly. Estrada de Ferro Campos do Jordão, uma abordagem. Campos do Jordão: Memórias Assessoria e Projetos, [2008]. Disponível em:

http://www.efcj.sp.gov.br/Historia/BuscaArquivoDocumentosTecnicosld/78. Acesso em: 19 set. 2020.

SANT'ANNA NETO, João Lima. A gênese da climatologia no Brasil: o despertar de uma ciência. Geografia, Rio Claro, v. 28, n. 1, p. 5-27, jan./abr. 2003.

SANTOS, Milton. Metamorfoses do espaço habitado: fundamentos teórico e metodológico da geografia. São Paulo: Hucitec, 1988.

SÃO JOSÉ DOS CAMPOS. Prefeitura Municipal. História: características, aspectos históricos e culturais. São José dos Campos: Prefeitura, 2019. Disponível em: https://www.sjc.sp.gov.br/servicos/governanca/sao-jose-em-dados/historia. Acesso em: 29 set. 2019.

SÃO PAULO (Estado). Lei n. 2.140, de 01 de outubro de 1926. Cria uma Prefeitura Sanitária em Campos do Jordão e autorisa a acquisição do todos os bens pertencentes a Companhia Guarujá. São Paulo: Secretaria de Estado dos Negócios do Interior, 1926. Disponível em: https://www.al.sp.gov.br/repositorio/legislacao/lei/1926/lei-2140-01.10.1926.html. Acesso em: 19 set. 2019.

SILVA JÚNIOR, Marcelo Henriques da; ROSENDO, Eliamin Eldan Queiroz; FILGUEIRA, Hamilcar José Almeida; SARMENTO, Francisco Jácome; SOUZA, Bartolomeu Israel de. Classificação climática de Thornthwaite: uma proposta de adaptação para a região semiárida brasileira (Thornthwaite's climate classification: an adaptation proposal for the Brazilian semiarid). Revista Brasileira de Geografia Física, Recife, PE, v. 10, n. 6, p. 1760- 
1774, ago. 2017. Disponível em: https://periodicos.ufpe.br/revistas/rbgfe/article/view/234079. Acesso em: 19 nov. 2019.

VIANA, Juliana Eliza; AUCIELLO, Michelle Ferreira; MARTINS, Nara Rubia; PAPALI, Maria Aparecida. Os abandonados da tuberculose: um olhar sobre São José dos Campos. In: ZANETTI, Valéria (org.). Fase sanatorial de São José dos Campos: espaço e doença. São José dos Campos, SP: UniVap, 2010. p. 285-307.

VIANNA, Paula Vilhena Carnevale; ZANETTI, Valéria; PAPALI, Maria Aparecida. Geografia, saúde e desenvolvimento urbano no interior paulista na passagem para o século $X X$ :

Domingos Jaguaribe e a construção da Estância Climática de Campos do Jordão. História, Ciências, Saúde - Manguinhos, Rio de Janeiro, v. 21, n. 4, p. 1341-1360, dez. 2014. Disponível em: http://www.scielo.br/scielo.php?script=sci_arttext\&pid=S0104$59702014000401341 \&$ Ing=en\&nrm=iso\&tlng=pt. Acesso em: 20 out. 2019.

VICENTINA Aranha: fotógrafo desconhecido: 1950. 2017. São José dos Campos: PróMemória, 2017. Disponível em:

http://www.camarasjc.sp.gov.br/promemoria/2017/05/17/vicentina-aranha-fotografodesconhecido-1950/. Acesso em: 19 nov. 2019.

YNOUE, Rita Yuri; REBOITA, Michelle S.; AMBRIZZI, Tércio; SILVA, Cyrlene A. M. da. Meteorologia: noções básicas. São Paulo: Oficina de Textos, 2017.

ZANETTI, Valéria; PAPALI, Maria Aparecida; DEL OLMO, Maria José Acedo; VIANNA, Paula Vilhena Carnevale. O boletim médico: prescrição dos tisiólogos para a cura da cidade de São José dos Campos (1930-1935). História, Ciências, Saúde-Manguinhos, Rio de Janeiro, v. 17, n. 3, p. 719-737, 2010. Disponível em:

http://www.scielo.br/scielo.php?script=sci_arttext\&pid=S0104-

$59702010000300009 \& \mathrm{lng}=\mathrm{pt} \& \mathrm{nrm}=$ iso. Acesso em: 16 out. 2019.

Recebido: julho de 2020. Aceito: outubro de 2020. 